\title{
Mobilizing and training academic faculty for medical mission: current status and future directions
}

\author{
James D Smitha, Roger P Holland ${ }^{b}$, J Dwight Phillips ${ }^{c}$, Sharon A Falkenheimer ${ }^{d}$ \\ ${ }^{a}$ MD, Professor Emeritus, Oregon Health and Science University, Portland, Oregon, United States \\ ${ }^{\mathrm{b}} \mathrm{MD}$, Dean, MyungSung Medical College, Addis Ababa, Ethiopia \\ ${ }^{\mathrm{c}} \mathrm{MD}$, Professor of Pediatrics, Department of Pediatric and Adolescent Medicine, Mayo Clinic, Minnesota, United \\ States \\ ${ }^{d}$ MD, MPH, MA, Academy of Fellows, Center for Bioethics and Human Dignity, Trinity International University, \\ Deerfield, Illinois, United States
}

\section{Introduction}

International professional education represents an expanding frontier for medical missions. In November 2015, 67 medical missionaries and academicians met in conjunction with the Global Missions Health Conference (GMHC) in Louisville, Kentucky. Most of the participants involved in the discussion were of North American origin, some originated and resided on other continents, and most participants had spent years working professionally outside of North America. They reviewed the current situation of international medical education missions and discussed future directions. A subgroup of 14 educators held specific discussions about mobilizing medical educators from high income countries (HICs) and then reviewed their findings with the entire group. Additional discussions have been held since the November 2015 meeting. Arising from those discussions, this paper represents a consensus about the current status of mobilization of academic medical faculty in missions and about future directions recommended by the group.

The workgroup divided up its discussion between short- (less than 2 years) and long-term (more than two years) missions and then focused the discussion on the following topics: 1) Current status, 2) Identifying and mobilizing faculty, 3) Medical school needs in low- and middle-income countries (LMICs), 4) Motivation for participation, 5) Barriers to participation in medical education missions, 6) Issues in medical education missions, 7) Recommendations for future efforts, and 8) Best practices.

\section{Current status}

In the last several years, there has been an increasing recognition that treating individual patients in hospitals by expatriate health care professionals is neither sustainable nor capable of building long-term capacity. The result is an increasing interest in education by starting medical and dental schools, nursing schools, post graduate (resident) training, and training in the paramedical professions. ${ }^{1}$ It is also recognized that sending nationals from LMIC to HIC countries for training will result in a high percentage staying in the HIC where they train, supplementing the health care force in that country, but doing nothing of lasting importance for their country of origin. When a country is dependent upon the presence or absence of expatriate professionals, it creates inherent instability in the medical care capacity, constant turnover, and an inability of the countries' health professions to mature and reproduce themselves and their programs. ${ }^{2}$ In this time of transition from expatriate to national medical educators, it is imperative that the goal be not just to produce new

Nov 2016. Christian Journal for Global Health, 3(2): 168-175. 
health care professionals, but that a cadre of educators be developed to take on the roles of modeling, encouraging, and training the teachers how to teach, especially with the types of interactive teaching methods recommended by medical education leaders ${ }^{3,4}$ rather than pure lecture/memorization.

\section{Identifying and mobilizing faculty}

Traditionally medical missions have been considered the purview of doctors and nurses, giving direct medical care and not been seen as an area for basic science teachers, academics, researchers or subspecialists. Many of these nonphysician/nurse teachers feel marginalized when it comes to contributing tangibly to missions, and they feel the only way to participate is to be involved with secular organizations and international meetings which are normally held in HIC. As Christian organizations see the need for medical and nursing schools, residency training and other health training programs, they realize that they need to mobilize an entirely new group of missionaries. To build the necessary foundation for this new educational endeavor, expatriate educators can, at least initially, build capacity by participating with health care educational professionals in LMIC, especially in the basic sciences, along with individuals who have experience in adult medical education methods. Those from LMIC with these qualifications are often already working in national universities or frequently already have emigrated to HIC. This is especially acute where groups have started new medical schools, specifically Christian medical schools and have not been able to find basic science faculty. In some countries, it has been possible to hire faculty from secular schools to teach courses, but this usually means to come for short-term periods and give a modular series of lectures. Even this option may not work in schools without a modular curriculum. The ability both to model Christian principles and to develop teaching skills is a long-term process that depends upon building trusting relationships with local faculty. Some present short-term visits tend to result in minimal interaction between the students and faculty and provide mainly rote memory learning. ${ }^{5}$ This is not just a problem for Christian schools, but also occurs in new secular government schools as witnessed by some of the participants in Indonesia and elsewhere. To improve this situation will require the goal of training teachers at all levels.

Since this is a growing area of educational need, we must look at how we can mobilize an entirely new group of educators to consider medical education missions in their career plans. When one considers working with students as a mission field to represent Christ, there are great possibilities for multiplicative impact when compared to treating individual patients. Not only does one have the possibility of training the next generation of health care providers, thus changing medical care in the country, but one is also modeling a Christ-like approach to caring for patients. As trainees learn to be Christ's witnesses, they are well-suited to reach their own people as they know the culture and the language better than any expatriate. In this way, equipping local health care providers as educators can become a sustainable program. Does this mean there will be no role for missionaries sometime in the future? No, but the roles will change. The new missionaries will be colleagues who provide resources for partnering with local health care providers in maintaining skills, and acting as mentors and role models. This is truly an exciting multiplicative opportunity for missionary health care providers-educators.

\section{Medical school needs in LMICs}

Traditionally medical mission agencies sent expatriate doctors and nurses to staff smaller rural mission hospitals, and nurses to staff rural clinics. While Christian missionaries have already been leaders in primary and secondary education, in many LIC, there have been relatively few efforts in post-secondary school education, especially in

Nov 2016. Christian Journal for Global Health, 3(2): 168-175. 
medical education. Many mission hospitals, out of need, have started nurses training programs, but mainly serve local needs. Two exceptional Christian medical schools are the excellent medical school in Vellore, India, which is internationally recognized for its excellent training, and a more recent program in Africa at the Kilimanjaro Medical Center in Arusha, Tanzania. Both have maintained their Christian heritage, but not necessarily uniform Christian commitment among their staff.

In the last ten years, there has been an increasing interest in starting new medical schools, usually associated with Christian universities or stand-alone programs, especially in Africa. Several examples include schools in Ethiopia, Nigeria, Burundi, Kenya, and Swaziland, and there are plans for more in Zambia, Malawi, and Uganda. Along with these schools are new government-sponsored and private for-profit schools. ${ }^{6}$ It is recognized that there is a huge need to increase the health care workforce in LMIC, but there are two problems: (a) where to find basic science teaching faculty and (b) where to find clinical facilities with faculty willing to teach the "hands-on" clinical side of medical education. If the faculty and facilities are not adequate, teaching ends up focusing on lectures and rote memory with little or no direct patient care experience.

Another concern for the future is whether there will be post-graduate training and employment opportunities, especially for physicians since some LMIC, for financial reasons, train far more medical students than they can employ. The excess trained health care providers have to emigrate to other countries. This defeats one of the original purposes of starting new schools, filling manpower needs in the country.

These new medical schools, especially the Christian schools, have a huge need for teachers, especially those in the basic sciences, such as anatomy, histology, physiology, microbiology/ parasitology, pathology, and biochemistry. There will also be a need for teachers in the clinical years.
Since many of the new schools plan to use mission hospitals for their students' clinical experience, there is a need for faculty-development training that focuses on newer teaching methods for doctors already working in these settings as most do not come from an academic background and may feel inadequate to teach medical students. Finally, there will be a need for physician-scientists who can teach research methodology and mentor young physician scientists to seek out and conduct research projects; these projects should, ideally, be generated from within the LMIC and of direct relevance in the LMIC. Newly minted physicianscientists in LMIC need to be taught and mentored, otherwise research in LMIC will continue to be directed by overseas universities with budgets that are unrealistic for the LMIC to sustain on their own and that typically end when overseas researchers return home. One problem is that adding this load to an already overburdened mission hospital staff will be difficult. Because of the need, these schools may need to supplement their teaching by recruiting expatriate faculty willing to teach courses or modules online or by telemedicine. These activities could be supplemented by on-site instructors.

Another area to which some have been called is working in government/secular medical schools. There are many examples of Christians taking fulltime faculty positions to teach medical students in medical skill laboratories and clinical departments. Many times, where one is not allowed to practice medicine by the Ministries of Health (MOHs) licensing requirements, a limited license to teach medical students in a clinical setting may be granted. This may be a way to serve in creative access nations. Also, where there is an interest in starting Family Medicine training programs by the $\mathrm{MOH}$, but where the specialty has not been recognized, there will be a need for expatriates to help start and advise such programs. The need for teaching faculty may be divided into short-term (less than 2 years) and long-term (more than 2 years). The most pressing need is for long-term committed individuals to provide continuity for the

Nov 2016. Christian Journal for Global Health, 3(2): 168-175. 
medical students, but more importantly to equip nationals to take over and maintain the school. This does not negate the value of short-term faculty for these new schools, at least in the near future.

\section{Motivation to serve in medical education missions}

The Working Group noted several motivational factors among those who the Lord has called to serve this way in medical education missions. While these factors vary in importance, the most vital is that there be spiritual motivation and direction to maximize the "Christian" value of international medical education. Common and relevant motivational factors include:

- First, a call from the Lord to serve in this setting, followed by a response to the command (while going) to follow Christ's example to "teach and heal,"

- A recognition of humanitarian needs and a desire to serve those with relatively fewer educational resources,

- A desire for relationship with people from other cultures and to contribute positively to other groups,

- A response to "peer pressure" related to a broad interest in North America on "paying back" and global health,

- A recognition of the benefits and potential long term impact of multiplication and capacity building through health care provider education compared to providing direct patient care,

- Personal invitation to go with someone or visit a facility,

- Academic benefits to participants' curriculum vitae, participation in research, and international networking,

- Desire for family to experience "missions" and other cultures, and,

- Personal enjoyment of adventure or travel.

\section{Barriers to participation in medical}

\section{education missions}

As there are motivational factors for being involved with missions through teaching, the Working Group also identified several barriers to serving. These may include the following:

\section{Short term missions}

- Busy professional and family schedules,

- Institutional constraints (call schedules and vacation planning often done far in advance) restricting ability to leave on short notice. There are also economic factors when departments require faculty to do clinical work for income to the department or medical school, which may limit the time someone can be away.

- Limitations due to school schedules for those in academics or their children,

- Priority given to direct patient care missions versus educational missions by either the individual or institutions,

- Cost, especially for those with lower salaries such as paramedical professionals, medical laboratory technicians, basic science teachers, researchers and retired individuals,

- Perceived and real risks, and dangers to the individual and/or family members,

- Unfamiliarity with or fear of local disease, especially in tropical countries,

- Lack of familiarity with intercultural expectations or barriers, and

- The need to teach through translators.

\section{Long term missions}

- Family needs or concerns,

- Children's education,

- Obligation to repay school-related debt,

- Requirement for language study,

- Obtaining a license in host country,

- Stepping off an academic career ladder,

- Local standards of teaching and assessments,

Nov 2016. Christian Journal for Global Health, 3(2): 168-175. 
- Unfamiliarity with diseases and conditions in tropical countries,

- Limited availability of facilities and infrastructure,

- Working with limited technology and equipment, especially in the surgical fields, and

- Problems with re-entry into home countries when leaving the field.

\section{Academic experience and qualifications}

Another area of consideration is whether people who have a call from the Lord need academic experience and credentials. This depends on the teaching situation, but it should usually be required that a health care educator going overseas have both appropriate cultural humility and adequate training in education. However, with newer education methods such as organ-based (e.g., modular) teaching, there is integration of purely basic science faculty with clinicians, both working together to teach the basic sciences. This gives medical students earlier clinical knowledge and experience than the traditional two years of basic sciences followed by two years of clinical experience. In these limited settings, clinical health care provider educators may not require academic experience, as long as they are current in their knowledge and practice. The key requirement is that the person should have an interest in teaching and be willing to help teach the clinical correlation of basic science topics. However, new long-term health care provider-educator missionaries will need training in faculty development topics and experience in teaching to equip local health care providers as educators. Short-term educators with academic experience can also contribute to the effort to train trainers. Eventually, faculty development for basic and clinical science teachers in the LMIC will be needed as well. This will require not only training in the usual areas for new missionaries such as cultural awareness, language training, and Biblical training, but also now topics such as lecture preparation, adult learning theory, small group teaching, and assessment methods. All of this may seem daunting and discourage some, but there are many resources already available to those pursuing health care education missions. Most medical schools have modules for faculty development topics, which may be open to nonfaculty members. There are online resources and even online medical education masters degrees and online certificates. ${ }^{7,8}$

\section{Pre-field training for medical education missionaries}

One problem for medical education training is that missionaries are sent out by a number of different mission/church organizations, but they are trained in the same topics as all the missionaries going to the field, such as church planting and seminary training and not in medical education topics. ${ }^{9}$ Various sending organizations could combine to provide specific pre-field training for medical educators. One effort to bring new medical missionaries together for this type of training is the Christian Medical and Dental Associations' Center for Medical Missions pre-field training course which is offered two to three times each year. ${ }^{10}$ However, there are currently no sessions specific to equipping in medical education methods and practices. Additional sessions for those involved with health care education could be added to this and other missionary meetings such as the Global Missions Health Conference (GMHC) ${ }^{11}$ and the CMDA-affiliated annual overseas conference for missionaries. Stand-alone courses could also be offered, perhaps by CMDA's Medical Education International ministry. An internationally available equipping effort is also conducted by the UK Christian charity, PRIME: Partnerships in International Medical Education. ${ }^{12}$ PRIME has excellent, free curricula and courses in whole person care and interactive teaching methods; these have been implemented in many nations and cultures.

Nov 2016. Christian Journal for Global Health, 3(2): 168-175. 


\section{Recommendations for future efforts}

Since international medical education is a new area of recruitment it will require new initiatives. There could potentially be a central clearinghouse available to individuals or mission organizations interested in health care education. The www.medicalmissions.com/network/ education website has started pulling some information together. At present, Samaritan's Purse/World Medical Missions provides a database of needs for medical missionaries requested by mission hospitals. They send out bimonthly updated information, recognizing those who have served and needs requested by mission hospitals. They also help provide travel arrangements for those wishing to serve. Something similar is needed for those interested in health care education. Samaritan's Purse already helps the Pan African Academy of Christian Surgeons (PAACS) recruit and send short term surgical educators. They also provide a two-year fellowship for finishing residents who want to do missions but have large debt loads. They help them find opportunities to serve, but thus far, that service is focused on clinical care rather than medical education. Expenses are covered during that period, but for the recipients to continue on the field, they need to return to their home country to find a sending organization and raise support. These two things, plus many times burnout by the individual and/or family, have resulted in a relatively low retention rate. Another organization that helps potential health care professionals stay on the field is Project MedSend. ${ }^{13}$ Most individuals graduating from a health care field have a large debt load. MedSend and some US governmental organizations help by covering the cost of education debt payments while health care workers are on the field.

Recruiting new missionaries for areas of medical education will need a multi-pronged approach. Recruitment has traditionally been by personal involvement of missionaries speaking and presenting a compelling story of how the Lord uses missions to reach unreached people groups and especially stories of how mission hospitals can heal people physically and spiritually. The venue is usually in churches or mission conferences such as Urbana or GMHC. Since there are very few missionaries engaged in health care education, potential missionaries and mission organization have not been exposed to the value of such efforts. It will take time, but everyone interested in this area needs to look for speaking opportunities to disseminate the message. There are many opportunities that have not been tapped, such as speaking at local CMDA chapters. The key is networking to receive invitations to speak. One group that is difficult to reach are those in basic sciences since they do not usually consider missions as an area where they may serve! The key to reaching this group is going to be clinical colleagues who are made aware of opportunities and who can then reach out to this group.

An opportunity to reach a large number of young people interested in missions is the annual GMHC meeting. Workshops and exhibits are opportunities to meet and encourage young people to consider medical education missions as a way to serve the Lord. Groups such as PAACS and Medical Education International (MEI) find this meeting one of the best areas to recruit and network.

Another recruitment tool would be short term "vision trips" that could be sponsored by individuals, mission groups, or educational institutions. The idea would be that someone who visits and gets involved will see the potential opportunities and have a desire to participate longer term or on repeated trips.

Probably the most fruitful recruitment is by personal invitation from those interested in health care education. It is imperative that those of us who have an interest in this field seek out opportunities to deliver this message.

Nov 2016. Christian Journal for Global Health, 3(2): 168-175. 


\section{Best practices}

There is a need to continue to develop and disseminate best practices in medical education missions. Most international medical schools will have a curriculum designed by the local government to approve the school and its graduates. It will be necessary to work within these guidelines, but people who are called to serve can still use the latest teaching and adult education methods. Other curricular topics that need to be introduced relate to medical ethics and the concepts of ambulatory and preventive medical care. Of course, these methods will need to be made culturally relevant to the country where the teaching takes place. For both short- and long-term participants, having training sources in the form of online courses or educational conferences would be useful. It would be best if these could be coordinated by a central organization. Having a toolkit of lectures, PowerPoint presentations, videos, webinars, and educational resources available for people to use would be useful. Again, this would require a central clearing agency. The provision of information would need to be supplemented by personal relational connections to maximize the value of the education. Some groups that could be resources for information are the Society of Teachers of Family Medicine, MedSend, and leaders in North America with connections to global health training programs.

One encouraging development is the desire for indigenous health care workers and medical missions to cooperate and work together rather than working in separate "silos." 14 This will continue to require mutual respect and a willingness to work together as partners.

\section{Conclusion}

As mission groups become involved with health care education in LMIC, it will be necessary to recruit a new cadre of missionaries that are interested and knowledgeable about current educational methods. There is a special need for educators in the area of basic sciences as well as those willing to be teachers in the clinical hands-on areas. There are several motivational factors for individuals to serve in these opportunities, but foremost there must be a call from the Lord. There are also many barriers to participation, especially for those in academic careers. To find and equip these new missionaries will require the cooperation of mission groups and organizations involved in starting new education endeavors. These groups need to develop "best practices" based on international educational standards, but also making them relevant to the local culture.

\section{References}

1. Magadza M. Swaziland: first school of medicine to be built [Internet]. U World News. 2011 July 03;80(5).

2. Firsing S. How severe is Africa's brain drain? Quartz Africa. 2016 Jan 21.

3. Cooke M, Irby DM, O'Brien BC; Carnegie Foundation for the Advancement of Teaching. Educating physicians: a call for reform of medical school and residency. San Francisco: Jossey-Bass; 2010.

4. Frenk J, Chen L, Bhutta ZA, Cohen J, Crisp N, Evans T, et al. Health professionals for a new century: transforming education to strengthen health systems in an interdependent world. Lancet (North American Edition). 2010;376(9756):1923-58. http://dx.doi.org/10.1016/S0140-6736(10)61854-5

5. Custers EJFM, Boshuizen HA. The psychology of learning. In Norman GR, Ven der Vleuten CPM, Newble DI, editors. International Handbook of Research in Medical Education, Part I. Kluwer Academic Publishers, 2002, Chapt. 5, p. 163-205.

6. Task Force for Scaling Up Education and Training for Health Workers, Global Health Workforce Alliance. Scaling up, saving lives [Internet]. World Health Organization. 2008. http://www.who.int/workforcealliance/documents/Gl obal_Health\%20FINAL\%20REPORT.pdf

7. Johns Hopkins University. Masters of Education in Health Professions [Internet]. [Cited 2016 October 8] Available from:

http://education.jhu.edu/Academics/masters/MEHP/

Nov 2016. Christian Journal for Global Health, 3(2): 168-175. 
8. University of New England. Master's of Science in Medical Education Leadership. [Internet] [Cited 2016 October 8] Available from: http://www.une.edu/com/mmel

9. Strand MA, Chen AI, Pinkston LM. Developing cross-cultural healthcare workers: content, process and mentoring, Christ J Glob Health. May 2016;3(1):57-72. http://dx.doi.org/10.15566/cjgh.v3i1.102

10. CMDA.org [Internet]. Bristol, TN: Christian Medical and Dental Associations. [Cited 2016 August 30]; Center for Medical Missions. Available from: https://cmda.org/missions/detail/cmm

11. CMDA.org [Internet]. Bristol, TN: Christian Medical and Dental Associations. [Cited 2016
August 30]; Global Missions Health Conference. Available from: https://cmda.org/missions/detail/cmm

12. PRIME: Partnerships in International Medical Education [Internet] [Cited 2016 Aug 30]. Available from: http://www.prime-international.org/home.htm

13. MedSend [Internet] [Cited 2016 Aug 30]. Available from: https://medsend.org/

14. Oman K, Khwa-Otsyula B, Majoor G, Einterz R, Wasteson A. Working collaboratively to support medical education in developing countries: the case of the friends of Moi University Faculty of Health Sciences. Educ Health. 2007;20:1-9. Available from: www.educationforhealth.net/

Competing Interests: None declared.

Correspondence: James D Smith, Oregon Health and Science University, Oregon, United States. jamesd.smith@yahoo.com Roger P Holland, MyungSung Medical College, Addis Ababa, Ethiopia. hollandinethiopia@gmail.com J Dwight Phillips, Department of Pediatric and Adolescent Medicine, Mayo Clinic, Minnesota, United States. jdwightphillips@gmail.com Sharon A Falkenheimer, Academy of Fellows, Center for Bioethics and Human Dignity, Trinity International University, Illinois, United States. shari.falkenheimer@cmda.org

Cite this article as: Smith JD, Holland RP, Phillips JD, Falkenheimer SA. Mobilizing and training academic faculty for medical mission: current status and future directions. Christian Journal for Global Health (Nov 2016), 3(2):168-175.

(C) Smith JD, Holland RP, Phillips JD, Falkenheimer SA. This is an open-access article distributed under the terms of the Creative Commons Attribution License, which permits unrestricted use, distribution, and reproduction in any medium, provided the original author and source are properly cited. To view a copy of the license, visit http://creativecommons.org/licenses/by/4.0/

\section{www.cjgh.org}

Nov 2016. Christian Journal for Global Health, 3(2): 168-175. 